\title{
Substituição parcial do milho por sorgo granífero na alimentação de matrizes suínas primíparas durante a lactação
}

[Partial substitution of corn by sorghum in the feeding of primiparous female pigs during lactation]

F.R.C. Moreira ${ }^{1}$, A.N. Costa ${ }^{2}$, T.D.D.Martins ${ }^{3}$, J.H.V. Silva ${ }^{3}$, L.A.F. Pascoal ${ }^{3}$, G.R.B. $\mathrm{Cruz}^{3}$

\footnotetext{
${ }^{1}$ Aluno de pós-graduação - Universidade Federal da Paraíba - Areia, PB - IFRN - Apodi, RN

${ }^{2}$ Bolsista DCR/CNPq - FAPERN/UFRN - Natal, RN

${ }^{3}$ CCHSA-UFPB - Bananeiras, PB
}

\section{RESUMO}

Avaliou-se o efeito da substituição parcial do milho por sorgo granífero na dieta de matrizes suínas híbridas durante as fases de lactação e pós-desmame. Foram utilizadas 25 fêmeas, distribuídas em três tratamentos, com porcentagens crescentes de sorgo granífero - 0\%, 25\% e 50\% - em substituição ao milho. Os animais foram avaliados durante as fases de lactação e pós-desmame, tendo sido mensurados o peso vivo (PV) e a espessura de toucinho (ET) ao parto, ao oitavo, $16^{\circ}$ e $25^{\circ}$ dias de lactação - desmame. Nesses momentos, foram realizadas colheitas de amostras de leite para análise bioquímica. As leitegadas foram pesadas no mesmo intervalo de tempo. No estro pós-desmame (RE), determinou-se o intervalo estro-cobertura (dias), PV e ET. Quanto às fêmeas, não ocorreram efeitos sobre o PV e a ET. Quanto ao número e ao peso dos leitões, as fêmeas do grupo controle apresentaram maior número de leitões nascidos vivos. O GPD dos leitões foi maior nas leitegadas dos tratamentos com 50\% de sorgo. Não houve diferença para as análises do leite. No RE, não ocorreram efeitos. Dessa forma, conclui-se que o sorgo granífero pode substituir o milho em até $50 \%$ na dieta de fêmeas suínas durante lactação, sem comprometer os parâmetros produtivos e reprodutivos.

Palavras-chave: alimento alternativo, fêmeas suínas, reprodução

\section{ABSTRACT}

The aim of this research was to evaluate the effect of partial substitution of corn with sorghum on the diets of hybrid female pigs during lactation and post-weaning. Twenty-five females were distributed in three treatments with increasing levels of grain sorghum -0\%, 25\% and 50\% - as partial substitute of the corn. The females were evaluated during the lactation and post-weaning phases, measuring live weight $(L W)$ and age at puberty and $L W$ and backfat thickness (BT). The females were weighed on the $8^{\text {th }}, 16^{\text {th }}$ and $25^{\text {th }}$ days of lactation (weaning), simultaneously with the measurement of BT and milk samples for biochemical analysis. Also, the litters were weighed at the same interval. The estrus detection after weaning was determined by the rangetopping estrus (days), LW and BT. As for females, there was no effect on LW and BT. As to the piglets number and weight, the females in the control group had a high number of piglets born alive. The daily gain of piglets was higher in litters with treatment with 50\% sorghum. There was no difference in the milk analysis. In the post-weaning there were no effects. Thus, it was concluded that grain sorghum can replace corn by 50\% on the diet of female pigs during lactation without compromising the productivity and reproductive parameters.

Keywords: alternative feed, female pigs, reproduction

\section{INTRODUÇÃO}

As suinoculturas brasileira e mundial alternam momentos de expansão e retração ao longo dos últimos anos, o que interfere na eficiência econômica da atividade. Essa instabilidade

Recebido em 11 de outubro de 2012

Aceito em 14 de dezembro de 2013

E-mail: faviano_moreira@hotmail.com incentiva $o$ mercado a buscar alimentos alternativos ao milho e à soja, com o objetivo de reduzir custos.

A produtividade de uma granja de suínos pode ser avaliada pela sua eficiência reprodutiva, representada pelo número de leitões terminados 
por matriz ao ano, que, por sua vez, é influenciado pelo número de leitões nascidos vivos e pelo número de partos por fêmea ao ano. O desempenho das matrizes, entretanto, é dependente de fatores como genética, manejo, ambiente e nutrição, que influenciam diretamente a produtividade da empresa suinícola (Paiva et al., 2005).

As matrizes suínas, principalmente primíparas, dependem de um aporte adequado de nutrientes para uma melhor produtividade ao longo de sua vida útil (Oelke et al., 2008). Dessa forma, para o uso de qualquer alimento alternativo, como o sorgo, é necessário aprofundar os conhecimentos sobre os seus efeitos biológicos nos animais.

O sorgo é tido como o quinto cereal mais importante no mundo e possui como vantagens a resistência à seca e o uso em solos arenosos $(\mathrm{Gu}$ et al., 2008; Cerisuelo et al., 2012) e em regiões semiáridas (Niba et al., 2013). Apesar das vantagens, o sorgo tem sido pouco utilizado nas dietas de não ruminantes, devido, em parte, ao conteúdo de tanino e ao menor teor de lisina de algumas variedades (Nyannor et al., 2007; Manuel et al., 2012).

Com base nessas informações, objetivou-se estudar a substituição parcial do milho por sorgo granífero com baixo teor de tanino sobre o desempenho de matrizes suínas híbridas durante as fases de lactação e pós-desmame.

\section{MATERIAL E MÉTODOS}

Foram utilizadas 25 leitoas híbridas de linhagem comercial (Camborough $\mathrm{F} 2{ }^{\circledR}$ ), durante as fases de lactação e estro pós-desmame do primeiro ciclo reprodutivo, distribuídas em um delineamento experimental inteiramente ao acaso, com três tratamentos, correspondentes a $0 \%(n=8), 25 \%(n=10)$ e $50 \%(n=7)$ de sorgo granífero em substituição ao milho e cinco repetições de uma leitoa cada.

As rações experimentais foram compostas principalmente por milho, sorgo, farelo de soja, e suplementadas com vitaminas e minerais para atender as exigências nutricionais descritas por Rostagno et al. (2005) para cada fase experimental. Foi utilizado o sorgo genótipo IPA 7301011, considerado de baixo tanino (Tabosa $e t$ al., 1999).

As fêmeas foram arraçoadas com as mesmas porcentagens de sorgo nas fases de puberdade e gestação. Durante a lactação e no pós-desmame (Tab. 1), as fêmeas foram alimentadas à vontade. $\mathrm{O}$ fornecimento de água também foi à vontade.

As fêmeas foram alojadas individualmente em baias a partir dos 100 dias de gestação, onde permaneceram até a cobertura pós-desmame. As pesagens e a espessura do toucinho (ET) foram realizadas ao parto, no oitavo, $16^{\circ}$ e $25^{\circ}$ dias de lactação e no primeiro estro pós-desmame. As medidas de ET foram obtidas por meio de aparelho de ultrassom (Modelo MTU-100, Microem Produtos Médicos Ltda., SP), entre a penúltima e a última costela, a $6,5 \mathrm{~cm}$ da linha média dorsal, nos lados direito e esquerdo, para o cálculo da média.

Com base nas pesagens e mensurações de ET, foi avaliada a variação de peso durante a lactação (do parto ao oitavo dia, do parto ao $16^{\circ}$ dia e do parto ao $25^{\circ} \mathrm{dia}$ ), pós-desmame (do desmame ao estro subsequente) e da cobertura ao desmame.

Para a determinação do intervalo desmame-estro (IDE), a partir do terceiro dia após o desmame, realizou-se a detecção do estro, duas vezes ao dia, por meio do reflexo de tolerância ao homem na presença do macho.

$\mathrm{Na}$ assistência aos partos, foi registrado o número de animais nascidos totais (NT), nascidos vivos (NV), natimortos (NAT) e mumificados (MUM). Os leitões nascidos vivos foram manejados de forma convencional (corte e tratamento do umbigo, aplicação de 200mg de ferro dextrano no terceiro dia de vida e castração dos machos aos 10 dias de idade). Os leitões tiveram livre acesso à água desde o nascimento e à ração pré-inicial a partir do sétimo dia de vida. Ao nascimento e no oitavo, $16^{\circ}$ e $25^{\circ}$ dias de lactação (desmame), foram mensurados o peso $(\mathrm{kg})$ e o número de leitões para cálculo do peso médio $(\mathrm{kg})$ e do ganho de peso diário do leitão (g). 
Tabela 1. Composição alimentar ( $\mathrm{g} / \mathrm{kg}$ de matéria natural) e valores calculados (\%) das rações experimentais para as fases de gestação e lactação*

\begin{tabular}{|c|c|c|c|}
\hline \multirow[b]{3}{*}{ Ingrediente } & \multicolumn{3}{|c|}{ Níveis de substituição do milho pelo sorgo granífero (\%) } \\
\hline & \multicolumn{3}{|c|}{ Lactação } \\
\hline & 0 & 25 & 50 \\
\hline Milho & 624,28 & 468,21 & 312,14 \\
\hline Sorgo baixo tanino & 0,00 & 156,07 & 312,14 \\
\hline Farelo de soja (45\%) & 283,18 & 273,22 & 263,26 \\
\hline Óleo de soja & 38,73 & 38,86 & 38,98 \\
\hline Glúten de milho (60\%) & 8,85 & 15,25 & 21,64 \\
\hline Fosfato bicálcico & 18,64 & 18,60 & 18,57 \\
\hline Calcário & 7,24 & 7,30 & 7,36 \\
\hline Sal comum & 4,56 & 4,63 & 4,68 \\
\hline L-Lisina HCL & 2,17 & 2,50 & 2,83 \\
\hline L-Treonina & 0,23 & 0,28 & 0,32 \\
\hline DL-Metionina & 0,00 & 0,00 & 0,00 \\
\hline Premix vitamínico ${ }^{1}$ & 4,00 & 4,00 & 4,00 \\
\hline Premix mineral $^{2}$ & 0,50 & 0,50 & 0,50 \\
\hline Inerte $^{3}$ & 7,52 & 10,48 & 13,48 \\
\hline BHT (antifúngico) ${ }^{4}$ & 0,10 & 0,10 & 0,10 \\
\hline Total (g) & 1000,00 & 1000,00 & 1000,00 \\
\hline \multicolumn{4}{|l|}{ Valores calculados } \\
\hline Energia metabolizável (Mcal/kg) & 3,330 & 3,330 & 3,330 \\
\hline Proteína bruta (\%) & 19,00 & 19,00 & 19,00 \\
\hline Cálcio (\%) & 0,850 & 0,850 & 0,850 \\
\hline Fósforo disponível (\%) & 0,450 & 0,450 & 0,450 \\
\hline Lisina total $(\%)$ & 1,122 & 1,122 & 1,122 \\
\hline Metionina+cistina total (\%) & 0,613 & 0,610 & 0,607 \\
\hline Metionina total (\%) & 0,303 & 0,304 & 0,305 \\
\hline Treonina total $(\%)$ & 0,752 & 0,752 & 0,752 \\
\hline Triptofano total (\%) & 0,224 & 0,224 & 0,224 \\
\hline Gordura (\%) & 6,419 & 6,342 & 6,265 \\
\hline Fibra bruta $(\%)$ & 2,903 & 2,894 & 2,886 \\
\hline
\end{tabular}

${ }^{1}$ Quantidade por kg do produto: vit. A $225.000 \mathrm{UI}$, vit. $\mathrm{D}_{3} 37.500 \mathrm{UI}$, vit. E 1.500mg, vit. K 75mg, vit. B12 625mg, niacina $1.000 \mathrm{mg}$, ácido pantotênico $500 \mathrm{mg}$, ácido fólico $65 \mathrm{mg}$, biotina $6,75 \mathrm{mg}$, colina $8.400 \mathrm{mg}$, piridoxina $100 \mathrm{mg}$, riboflavina $150 \mathrm{mg}$, tiamina $32,5 \mathrm{mg} .{ }^{2}$ Quantidade por $\mathrm{kg}$ do produto: cobre $450 \mathrm{mg}$, ferro $2.750 \mathrm{mg}$, fósforo $85 \mathrm{mg}$, flúor $850 \mathrm{mg}$, iodo $17,5 \mathrm{mg}$, manganês $1.250 \mathrm{mg}$, selênio $7,5 \mathrm{mg}$, sódio $49 \mathrm{mg}$, zinco $2.750 \mathrm{mg}$, cromo $5 \mathrm{mg}$, bacitracina de zinco $1.000 \mathrm{mg} .{ }^{3}$ Inerte $=$ areia lavada. ${ }^{4} \mathrm{BHT}=$ butil-hidroxitolueno. $*$ Valores propostos por Rostagno et al . (2005).

Foi realizada a análise bioquímica do leite das porcas no Laboratório de Análise de Alimentos da Universidade Federal da Paraíba, em Bananeiras - PB. A determinação dos teores de matéria seca $(\%)$, gordura $(\%)$, lactose $(\%)$, proteína (\%) e cinzas (\%) foi obtida das amostras de leite colhidas aos oito, 16 e 25 dias de lactação. Para a obtenção do leite, foram aplicadas 10UI de ocitocina intramuscular nas matrizes, e, em seguida, um pool de tetas foi ordenhado. As amostras foram acondicionadas em recipientes estéreis e armazenadas a $-5^{\circ} \mathrm{C}$ para posterior análise. Os teores de matéria seca, proteína e cinzas foram determinados de acordo com AOAC (1998). O conteúdo de gordura foi obtido por meio do método de Gerber, adaptado por Martins et al. (2007), e a análise da lactose pela técnica de redução de Fehling (Instituto..., 1985).

Os parâmetros estudados no experimento foram submetidos à análise de variância e de regressão por meio dos polinômios ortogonais. Para as variáveis que apresentaram números negativos (variação de peso e ET), foi realizada uma mudança de escala e utilizou-se logaritmo para aliar uma distribuição próxima da normalidade. Em todas as análises estatísticas utilizou-se o 
procedimento GLM no programa estatístico SAS (Statistical..., 2005) e as recomendações de Reis (2003).

\section{RESULTADOS E DISCUSSÃO}

Para os efeitos da substituição do milho pelo sorgo na lactação (Tab. 2), não foi observada diferença para o peso das fêmeas. No entanto, para a variação de peso entre zero e oito dias (L1), foi encontrado efeito linear $(y=-0,5821$ $\left.6,1642 \mathrm{x} ; \mathrm{R}^{2}=0,98\right)$, com o tratamento controle apresentando a menor perda $(\mathrm{P}<0,05)$. Nos demais períodos (L2 e LT), não foram observados efeitos das rações. Para a espessura de toucinho (ET) e no estro pós-desmame, não foram encontrados efeitos lineares dos tratamentos.

Tabela 2. Peso $(\mathrm{kg})$ e espessura de toucinho $(\mathrm{mm})$ na lactação e no pós-desmame de fêmeas suínas alimentadas com rações com 0,25 ou $50 \%$ de sorgo granífero em substituição ao milho

\begin{tabular}{|c|c|c|c|c|c|}
\hline & \multicolumn{3}{|c|}{$\begin{array}{l}\text { Nível de substituição do milho pelo sorgo } \\
\text { granífero }(\%)\end{array}$} & \multirow[t]{2}{*}{$\mathrm{CV}(\%)^{1}$} & \multirow{2}{*}{$\begin{array}{l}\text { Efeito } \\
\text { linear }\end{array}$} \\
\hline & 0 & 25 & 50 & & \\
\hline Estágio lactacional & \multicolumn{3}{|c|}{ Peso } & & \\
\hline Dia 0 & 174,1 & 178,5 & 182,3 & 8,0 & ns \\
\hline Dia 8 & 171,4 & 168,9 & 165,2 & 8,4 & ns \\
\hline Dia16 & 168,3 & 157,3 & 158,7 & 8,0 & ns \\
\hline Dia 25 & 164,8 & 157,7 & 151,9 & 9,6 & ns \\
\hline L1 (0-8 dias) & $-2,4$ & $-5,4$ & $-4,3$ & 75,5 & $*$ \\
\hline L2 (0-16 dias) & $-6,6$ & $-13,4$ & $-18,7$ & 76,0 & ns \\
\hline LT (0-25 dias) & $-9,9$ & $-14,3$ & $-23,5$ & 69,1 & ns \\
\hline Pós-desmame & 166,9 & 154,1 & 154,0 & 8,4 & ns \\
\hline Cobertura-desmame $^{2}$ & 25,9 & 21,9 & 24,3 & 51,6 & ns \\
\hline \multicolumn{6}{|c|}{ Espessura de toucinho } \\
\hline Dia 0 & 14,9 & 12,7 & 15,2 & 16,0 & ns \\
\hline Dia 8 & 14,2 & 12,5 & 14,8 & 16,9 & ns \\
\hline Dia16 & 14,7 & 12,7 & 13,6 & 14,9 & ns \\
\hline Dia 25 & 13,8 & 11,3 & 13,3 & 15,4 & ns \\
\hline LET (0-25) & $-1,1$ & $-1,1$ & $-1,9$ & 77,4 & ns \\
\hline Pós-desmame & 14,1 & 12,1 & 13,7 & 14,7 & ns \\
\hline $\begin{array}{l}\text { Intervalo desmame-estro } \\
\text { (dias) }\end{array}$ & 6,1 & 5,9 & 5,6 & 25,9 & ns \\
\hline
\end{tabular}

Percentual de perda de peso durante a lactação para os grupos com 0,25 e $50 \%$ de sorgo foi de 5,6; 8,0; e 16,9\%, respectivamente.

${ }^{1}$ Coeficientes de variação.

${ }^{2}$ Variação de peso entre a cobertura e o desmame.

L1 - variação de peso entre zero e oito dias de lactação; L2 - variação de peso entre zero e 16 dias de lactação; LT variação de peso entre zero e 25 (desmame) dias de lactação; LET - variação da espessura de toucinho entre zero e 25 dias de lactação.

$* y=-0,5821-6,1642 x\left(R^{2}=0,98\right)$.

Uma perda de peso durante a lactação é explicada pela redução do apetite, principalmente nas primeiras duas semanas, devido à concentração circulante ou à oxidação de ácidos graxos não esterificados e glicerol, ou a uma resistência insulínica em fêmeas pesadas (Schenkel et al., 2010). Na opinião desses autores, fêmeas lactantes que perdem mais de $8 \%$ de peso não devem ser acasaladas no primeiro estro pós- desmame, e sim recuperadas, para que a cobertura seja realizada no estro seguinte. No presente experimento, as fêmeas do tratamento com $50 \%$ de sorgo perderam 16,9\% (Tab. 2) de peso durante a lactação, sem consequências no retorno ao estro pós-desmame, todavia os efeitos sobre o número de leitões não foram mensurados no segundo parto.

Ao avaliarem dietas compostas principalmente por sorgo no desempenho de porcas em lactação, Louis et al. (1991) observaram que as fêmeas alimentadas com rações contendo milho 
apresentaram maior ingestão de alimentos e leitegadas mais pesadas ao desmame em comparação àquelas que receberam dietas com sorgo, provavelmente devido à estrutura proteica do grão do sorgo. Neste estudo (Tab. 2), não foram encontradas diferenças significativas $(\mathrm{P}>0,05)$ na variação de peso ao final da lactação.

Quando trabalharam com rações contendo $100 \%$ de sorgo como ingrediente energético na alimentação de fêmeas gestantes e lactantes (21 dias), Garcia-Castillo et al. (2004) registraram perda de peso entre o parto e o desmame de $18,77 \mathrm{~kg}$. Por sua vez, Coffey et al. (1994) também observaram uma perda de $22,18 \mathrm{~kg}$ de peso para fêmeas alimentadas com rações à base de sorgo (desmame de 21 dias). No presente estudo, foram observadas perdas $(\mathrm{P}>0,05)$ de $9,9 \mathrm{~kg}(0 \%), 14,3(25 \%)$ e $23,5 \mathrm{~kg}(50 \%)$.

Provavelmente, as diferenças entre os trabalhos ocorreram pela equalização das leitegadas e pelo período de lactação. Contudo, mesmo considerando que os tratamentos com sorgo ocasionaram maior perda de massa corporal durante a lactação, o retorno ao estro não foi comprometido, visto que os valores foram similares entre os tratamentos. Esse achado se assemelha aos encontrados por Tantasuparuk et al. (2001).

Com relação à espessura de toucinho (ET), não foram observados efeitos lineares $(\mathrm{P}>0,05)$ para a ET ao parto, ao desmame ( 25 dias) e no estro pós-desmame. Os resultados apresentados na Tab. 2 demonstram que as fêmeas perderam 1,1, 1,1 e $1,9 \mathrm{~mm}$ para os tratamentos com $0,25 \mathrm{e}$ $50 \%$ de sorgo, respectivamente. Em trabalhos de Knabe et al. (1996) e Spencer et al. (2003), as medidas de ET durante a lactação variaram entre reduções de 0,3 e $2,2 \mathrm{~mm}$ de ET em porcas lactantes alimentadas com sorgo e entre 0,6 e $3,4 \mathrm{~mm}$ em porcas alimentadas com milho. Willis et al. (2003) sugeriram que a perda de ET durante a lactação não deve exceder $2,0 \mathrm{~mm}$, para não afetar a fertilidade das matrizes. No presente estudo, todos os tratamentos apresentaram valores abaixo dos preconizados.

Estudo de metanálise realizado por Rossi et al. (2008), com porcas gestantes e lactantes, evidenciou que a variação da ET na lactação é influenciada pelo peso dos leitões no sétimo dia de vida e pelo ganho de peso da leitegada. Segundo os autores, o número de leitões desmamados por porca e o decréscimo na variação da ET estão associados a exigências mais elevadas do processo de lactogênese.

Os dados obtidos no retorno ao estro pósdesmame (Tab. 2) foram de 6,1; 5,9 e 5,6 dias para os tratamentos com 0,25 e $50 \%$ de sorgo, respectivamente, indicando que não houve diferença $(\mathrm{P}>0,05)$ entre os tratamentos, o que corrobora os achados de Cromwell et al. (1989) e Louis et al. (1991), que observaram um período de $\mathrm{RE}$ de 5,8 e 5,4 dias, respectivamente, para animais alimentados com rações contendo $100 \%$ de sorgo em substituição ao milho. Na opinião de Mellagi et al. (2010), nem sempre o catabolismo lactacional influencia o RE, ao contrário do desenvolvimento folicular e da qualidade embrionária.

$\mathrm{Na}$ Tab. 3, observa-se o efeito dos níveis de substituição do milho por sorgo granífero sobre o número e o peso de leitões e de leitegadas. Foi encontrado efeito linear para as características leitões nascidos totais, nascidos vivos, peso médio dos leitões no $16^{\circ}$ dia de vida, peso da leitegada ao parto, ganho de peso médio diário (GPD) dos leitões entre zero e 16 dias e GPD entre zero e 25 dias. As leitoas que consumiram ração contendo $50 \%$ de sorgo obtiveram em média 3,1 leitões nascidos vivos a menos do que aquelas alimentadas com a ração controle. Quanto ao peso dos leitões, as matrizes alimentadas com substituição do milho por $50 \%$ de sorgo granífero produziram leitões mais pesados no $16^{\circ}$ dia de vida $(\mathrm{P}<0,05)$, todavia apresentaram o menor peso $(\mathrm{P}<0,05)$ da leitegada ao parto (Tab. 3). Para o ganho de peso médio dos leitões (Tab. 3), as crias provenientes das porcas com substituição de $50 \%$ do sorgo por milho apresentam os maiores valores $(\mathrm{P}<0,05)$ durante a lactação.

Com relação ao número de leitões nascidos vivos, natimortos e mumificados, os dados encontrados diferem dos obtidos por Louis et al. (1991) e Ricalde e Lean (2002), ao trabalharem com rações contendo sorgo como ingrediente energético. Tais diferenças entre as pesquisas podem ser atribuídas à composição genética das matrizes, às formulações das rações, às variedades de sorgo utilizadas e às diferentes condições experimentais de cada pesquisa. 
Tabela 3. Número e peso médio $(\mathrm{kg})$ de leitões nascidos de fêmeas alimentadas com rações contendo $100 \%$ de milho e substituição de $25 \%$ e $50 \%$ de sorgo granífero

\begin{tabular}{|c|c|c|c|c|c|}
\hline & $\begin{array}{r}\text { Nível d } \\
\text { pelo }\end{array}$ & $\begin{array}{l}\text { tituiç } \\
\text { gran }\end{array}$ & $\begin{array}{l}\text { milho } \\
(\%)\end{array}$ & $\mathrm{CV}$ & Efeito \\
\hline & 0 & 25 & 50 & & \\
\hline Variáveis & Núme & leitõe & gada & & \\
\hline Nascidos totais (NT) & 13,4 & 11,4 & 10,3 & 26,3 & $*$ \\
\hline Natimortos (NAT) & 0,3 & 0,5 & 0,2 & 24,5 & ns \\
\hline Mumificados (MUM) & 0,3 & 1,1 & 0,3 & 28,3 & ns \\
\hline Nascidos vivos (NV) & 12,9 & 9,8 & 9,8 & 19,7 & $* *$ \\
\hline Ao $8^{\circ}$ dia de idade & 11,3 & 9,1 & 9,8 & 17,4 & ns \\
\hline Ao $16^{\circ}$ dia de idade & 10,4 & 8,9 & 9,8 & 19,6 & ns \\
\hline Ao $25^{\circ}$ dia de idade & 9,9 & 8,7 & 9,8 & 24,0 & ns \\
\hline
\end{tabular}

\begin{tabular}{|c|c|c|c|c|c|}
\hline & \multicolumn{4}{|c|}{$\begin{array}{c}\text { Peso médio dos leitões }(\mathrm{kg} / \mathrm{animal}) \text { e da } \\
\text { leitegada }(\mathrm{kg})\end{array}$} & \\
\hline Ao nascer & 1,59 & 1,57 & 1,72 & 11,23 & ns \\
\hline Ao $8^{\circ}$ dia de idade & 2,64 & 2,71 & 3,00 & 12,81 & ns \\
\hline Ao $16^{\circ}$ dia de idade & 3,99 & 4,41 & 4,89 & 13,18 & $* * *$ \\
\hline Ao $25^{\circ}$ dia de idade & 6,05 & 6,54 & 7,12 & 14,83 & ns \\
\hline Peso da leitegada ao parto $(\mathrm{kg})$ & 20,4 & 15,3 & 14,7 & 30,2 & $* * * *$ \\
\hline Peso da leitegada ao $8^{\circ}$ dia de idade $(\mathrm{kg})$ & 29,7 & 24,7 & 29,5 & 21,8 & ns \\
\hline Peso da leitegada ao $16^{\circ}$ dia de idade $(\mathrm{kg})$ & 41,7 & 39,2 & 47,9 & 24,1 & ns \\
\hline \multirow[t]{2}{*}{ Peso da leitegada ao $25^{\circ}$ dia de idade $(\mathrm{kg})$} & 59,7 & 55,2 & 69,7 & 23,6 & ns \\
\hline & \multicolumn{4}{|c|}{ Ganho de peso médio dos leitões(g) } & \\
\hline Ganho de peso médio/dia $(0-8$ dias $)(\mathrm{g})$ & 132,3 & 144,1 & 170,8 & 26,6 & ns \\
\hline Ganho de peso médio/dia $(0-16$ dias $)(\mathrm{g})$ & 150,2 & 178,6 & 203,4 & 20,4 & $* * * * *$ \\
\hline Ganho de peso médio/dia $(0-25$ dias $)(\mathrm{g})$ & 178,7 & 199,5 & 219,2 & 18,8 & $* * * * * *$ \\
\hline
\end{tabular}

O peso ao nascimento dos leitões não diferiu $(\mathrm{P}>0,05)$ ao parto e ao desmame, apenas no $16^{\circ}$ dia, quando os animais do tratamento com $50 \%$ de sorgo apresentaram o maior peso. Para o GPD dos leitões durante a lactação (zero e 25 dias), o tratamento com $50 \%$ de sorgo apresentou os melhores resultados $(\mathrm{P}<0,05)$, fato que pode ser influenciado pelo menor número de leitões no período.

Neste estudo, como não ocorreram diferenças significativas entre os grupos experimentais no peso ao desmame dos leitões, pode-se inferir que os tratamentos à base de sorgo, durante a lactação, não afetaram o desenvolvimento dos leitões quando comparados ao grupo arraçoado com dietas à base de milho.

Durante o período de lactação, Knabe et al. (1996) e Kiefer et al. (2007) não observaram diferenças no desempenho de leitões e de leitegadas provenientes de matrizes suínas alimentadas com sorgo granífero como alimento energético. Por outro lado, Louis et al. (1991) observaram leitegadas mais pesadas ao desmame quando provenientes de fêmeas alimentadas com milho em relação àquelas que receberam dietas contendo sorgo durante a gestação e a lactação. A inconsistência nos resultados constatada entre os trabalhos com relação ao ganho de peso dos leitões está relacionada aos níveis nutricionais da ração, à temperatura ambiental e à ordem de parto das porcas (Haese et al., 2010).

Quanto à análise bioquímica do leite (Tab. 4), a composição do leite das porcas não foi influenciada $(\mathrm{P}>0,05)$ pelos níveis de substituição do milho por sorgo granífero e pelos estágios de lactação. 
Tabela 4. Parâmetros bioquímicos do leite no oitavo, $16^{\circ}$ e $25^{\circ}$ dias de lactação de fêmeas suínas híbridas alimentadas com rações contendo $0 \%, 25 \%$ e $50 \%$ de sorgo granífero

\begin{tabular}{|c|c|c|c|c|c|c|}
\hline $\begin{array}{c}\text { Estágios de } \\
\text { lactação (dias) }\end{array}$ & $\begin{array}{c}\text { Nível de substituição do } \\
\text { milho pelo sorgo granífero } \\
(\%)\end{array}$ & $\begin{array}{l}\text { Gordura } \\
(\%)\end{array}$ & $\begin{array}{l}\text { Lactose } \\
(\%)\end{array}$ & $\begin{array}{l}\text { Umidade } \\
(\%)\end{array}$ & $\begin{array}{c}\text { Proteínas } \\
(\%)\end{array}$ & $\begin{array}{c}\text { Cinzas } \\
(\%)\end{array}$ \\
\hline \multirow{3}{*}{8} & 0 & 7,5 & 4,6 & 80,7 & 5,3 & 0,7 \\
\hline & 25 & 7,5 & 3,8 & 80,5 & 5,4 & 0,8 \\
\hline & 50 & 7,0 & 4,2 & 82,5 & 5,0 & 0,7 \\
\hline \multirow{2}{*}{\multicolumn{2}{|c|}{ Efeito linear }} & ns & ns & ns & ns & ns \\
\hline & & 21,5 & 24,1 & 2,2 & 9,07 & 12,6 \\
\hline \multirow{3}{*}{16} & 0 & 7,0 & 4,2 & 81,5 & 5,0 & 0,8 \\
\hline & 25 & 6,6 & 3,7 & 81,9 & 4,9 & 0,8 \\
\hline & 50 & 5,4 & 5,6 & 82,8 & 4,7 & 0,8 \\
\hline \multirow{2}{*}{\multicolumn{2}{|c|}{ Efeito linear }} & $\mathrm{ns}$ & $\mathrm{ns}$ & $\mathrm{ns}$ & ns & $\mathrm{ns}$ \\
\hline & & 26,4 & 22,06 & 2,0 & 12,4 & 12,6 \\
\hline \multirow{3}{*}{25} & 0 & 7,3 & 4,5 & 82,3 & 5,4 & 0,9 \\
\hline & 25 & 7,1 & 3,5 & 81,9 & 4,9 & 0,9 \\
\hline & 50 & 7,0 & 4,9 & 82,0 & 5,3 & 0,9 \\
\hline \multirow{2}{*}{\multicolumn{2}{|c|}{ Efeito linear }} & ns & ns & ns & ns & ns \\
\hline & & 19,5 & 16,4 & 2,1 & 10,7 & 8,2 \\
\hline
\end{tabular}

${ }^{1}$ Coeficiente de variação.

Os valores encontrados para os constituintes do leite foram similares aos registrados por Tilton et al. (1999) e Martins et al. (2007). Como os parâmetros bioquímicos do leite não foram diferentes nos tratamentos, pode-se especular que a utilização do sorgo não afetou a composição do leite. $\mathrm{Na}$ maioria das pesquisas, a manipulação das rações não influencia a produção de leite de fêmeas suínas, ao contrário do número e do peso dos leitões (Auldist et al., 2000).

\section{CONCLUSÕES}

A substituição de $50 \%$ do milho por sorgo granífero na dieta de matrizes suínas primíparas, durante as fases de lactação e pós-desmame, representa uma alternativa viável na sustentabilidade da suinocultura em clima tropical.

\section{REFERÊNCIAS}

ASSOCIATION Of Official Analytical Chemists - AOAC. Official methods of analysis. 16.ed. 4.rev. 2v., 1998.

AULDIST, D.E.; CARLSON, D.; MORRISH, L. et al. The influence of suckling interval on milk production of sows. J. Anim. Sci., v.78, p.20262031, 2000.
CERISUELO, A.; MOSET, V.; BONET, J. et al. Effects of inclusion of sorghum distillers dried grains with soluble (DDGS) in diets for growing and finishing pigs. Span. J. Agric. Res.,v.10, p.1016-1024, 2012.

COFFEY, M.T.; DIGGS, B.G.; HANDLIN, D.L. et al. Effects of dietary energy during gestation and lactation on reproductive performance of sows: A cooperative study. J. Anim. Sci., v.72, p.4-9, 1994.

CROMWELL, G.L.; HALL, D.D.; CLAWSON, A.J. et al. Effects of additional feed during late gestation on reproductive performance of sows: A cooperative study. J. Anim. Sci., v.67, p.3-14, 1989.

GARCÍA-CASTILLO, R.F.; GUTIÉRREZBAÑUELOS, H.; MELLADO-BOSQUE, M. et al. Cromo L-metionina en dietas basadas en sorgo y soya en cerdas primerizas. Rev. Agr. Nu. Ep., v.1, p.6-11, 2004.

GU, L.; HOUSE, S.E.; ROONEY, L.W. et al. Sorghum extrusion increases bioavailability of catechins in wealing pigs. J. Agric. Food Chem., v.56, p.1283-1288, 2008.

HAESE, D.; DONZELE, J.L.; OLIVEIRA, R.F.M. Avaliação de rações de alta densidade nutricional para porcas em lactação no verão. Rev. Bras. Zoot., v.39, p.1503-1508, 2010. 
INSTITUTO Adolfo Lutz. Normas Analíticas do Instituto Adolfo Lutz. 3.ed. v.1. São Paulo: IAL, 1985. 533p.

KIEFER, C.; FERREIRA, A.S.; DONZELE, J.L. et al. Níveis de treonina digestível em dietas para fêmeas suínas lactantes de médio potencial genético.Rev.Bras.Zoot.,v.36,p.1775-1782, 2007.

KNABE, D.A.; BRENDEMUHL, J.H.; CHIBA, L.I. et al. Supplemental lysine for sows nursing large litters. J. Anim. Sci., v.74, p.1635-1640, 1996.

LOUIS, G.F.; LEWIS, A.J.; PEO, E.R. Feeding value of grain sorghum for the lactating sow. $J$. Anim. Sci., v.69, p.223-229, 1991.

MANUEL, M.F.; CONSUELO, D.P.; OLGA, M.O. Digestibilidad y flujo de digesta ileal em cerdos alimentados com granos de sorgo rojo em la dieta. Rev. Eléctron. Vet. v.13, p.1-6, 2012.

MARTINS, T.D.D.; COSTA, A.N.; SILVA, J.H.V. et al. Produção e composição do leite de porcas híbridas mantidas em ambiente quente. Cienc. Rural, v.37, p.1079-1083, 2007.

MELLAGI, A.P.G.; ARGENTI, L.E.; FACCIN, J.E.G. et al. Aspectos nutricionais de matrizes suínas durante a lactação e o impacto na fertilidade. Act. Sci. Vet., v.38, p.181-209, 2010.

NIBA, A.T.; KOUCHIKA, H.; KUDI, A.C. et al. Effect of micro-organism and particle size on fermentation of sorghum and maize for poultry feed. Afr. J. Biotec., v.12. p.4147-4157, 2013.

NYANNOR, E.K.D.; ADEDOKUN, S.A.; HAMAKER, B.R. et al. Nutritional evaluation of high-digestible sorghum for pigs and broiler chicks. J. Anim. Sci., v.85, p.196-203, 2007.

OELKE, C.A.; DAHLKE, F.; BELTRANI, O.C. et al. Níveis de lisina digestível em dietas para fêmeas suínas primíparas em lactação. Acta Scient. Anim. Sci., v.30, p.299-306, 2008.

PAIVA, F.P.; DONZELE, J.L.; OLIVEIRA, R.F.M. et al. Lisina em rações para fêmeas suínas primíparas em lactação. Rev. Bras. Zoot., v.34, p.1971-1979, 2005.

REIS, J.C. Estatística aplicada à pesquisa em ciência veterinária. 1.ed. Olinda: JCR, 2003. $651 \mathrm{p}$.
RICALDE, R.H.S.; LEAN, I.J. Effect of feed intake during pregnancy on productive performance and grazing behaviour of primiparous sows kept in an outdoor system under tropical conditions. Liv. Prod. Sci., v.77, p.13-21, 2002.

ROSSI, C.A.R.; LOVATTO, P.A.; WESCHENFELDER, V.A. et al. Metanálise da relação entre espessura de toicinho e variáveis corporais e reprodutivas de porcas gestantes e lactantes. Cienc. Rural, v.38, p.206-212, 2008.

ROSTAGNO, H.S.; ALBINO, L.F.T.; DONZELE, J.L. et al. Tabelas brasileiras para aves e suínos - composição de alimentos $e$ exigências nutricionais. 2. ed. Viçosa: UFV, v.1, 2005. 186p.

SCHENKEL, A.C.; BERNARDIL, M.L.; BORTOLOZZO, F.P. et al. Body reserve mobilization during lactation in first parity sows and its effect on second litter size. Liv. Sci., v.132, p.165-172, 2010.

SPENCER, J.D.; BOYD, R.D.; CABRERA, R. et al. Early weaning to reduce tissue mobilization in lactating sows and milk supplementation to enhance pig weaning weight during extreme heat stress. J. Anim. Sci., v.81, p.2041-2052, 2003.

STATISTICAL Analysis System - SAS. User's guide. Version 9.0. Cary: 2005. (CD-ROM).

TABOSA, J.N.; LIMA, G.S.; LIRA, M.A. et al. Programa de melhoramento de sorgo e milheto em Pernambuco. In: QUEIRÓZ, M.A., GOEDERT, C.O.; RAMOS, S.R.R. Recursos genéticos e melhoramento de plantas para o Nordeste brasileiro. Petrolina-PE: Embrapa Semi-Árido, 1999. p.1-29.

TANTASUPARUK, W.; DALIN, A.M.; LUNDEHEIM, N. et al. Body weight loss during lactation and its influence on weaning-to-service interval and ovulation rate in Landrace and Yorkshire sows in the tropical environment of Thailand. Anim. Rep. Sci., v.65, p.273-281, 2001.

TILTON, S.L.; MILLER, P.S.; LEWIS, A.J. et al. Addition of fat to the diets of lactating sows: I. Effects on milk production and composition and carcass composition of the litter at weaning. J. Anim. Sci., v.77, p.2491-2500, 1999.

WILLIS, H.J.; ZAK, L.J.; FOXCROFT, G.R. Duration of lactation, endocrine and metabolic state, and fertility of primiparous sows. J. Anim. Sci., v.81, p.2088-2102, 2003. 